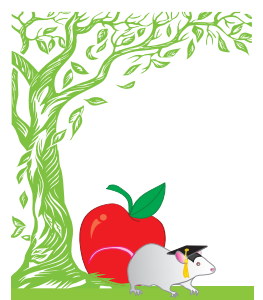

\title{
What's it all about, teacher?
}

Welcome to the inaugural edition of Fruits of Education, a column on training that I will be coordinating for Lab Animal each issue. I emphasize the word coordinate for several reasons: I am well acquainted with others in the laboratory animal training field with a diversity of experience in different aspects; I want to encourage others to contribute; and training is a team effort, not done to someone, but achieved by the willingness of many.

Why this title for the column? To begin with, there is a play on words, as you'll read here. The fruits of one's own labors in training and teaching pay off in innumerable ways, and it's very satisfying when the investment bears fruit. The image of an apple has long represented teachers. I have a small collection of apples in my office because of my association with teaching and training. Upon doing a Google search, I uncovered that fruit has been a traditional present for teachers in many countries, perhaps in part because teachers tend to be poorly paid and in part because classes start after the summer harvests in agrarian societies. The apple might impress the teacher, leading to a better grade, and the new school year would be off to a successful start. This also is the origin of the somewhat negative term 'apple polisher'. (Now, I tell my students to polish their apples when they submit a résumé assignment.) Additionally, the notion that eating apples conveys good health, as in the old adage 'an apple a day..., befits what we do in biomedical research.

It is anticipated in this column that, from time to time, Great Eastern University will request the assistance of trainers in addressing the issues raised in the Protocol Review column by Dr. Jerald Silverman.

The launch of this column is timely, with the continued increase in emphasis

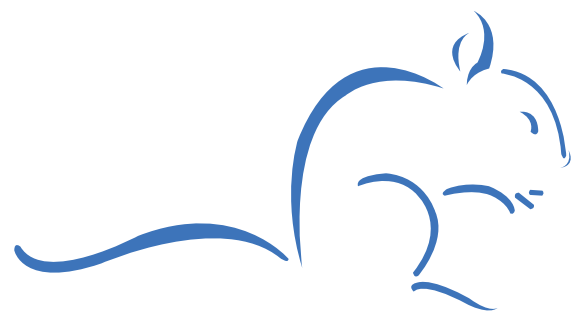

Laboratory Animal Welfare Training Exchange (LAWTE).

on training of laboratory personnel. The 2011 edition of the Guide for the Care and Use of Laboratory Animals (the Guide) ${ }^{1}$ uses the words 'training' and 'trained' 133 and 23 times, respectively. (Of those 156 combined instances, 23 occur in the index listing, confirming the importance of this topic.) Pages 15-17 are specifically devoted to training concerns that the IACUC should address. The frequency of 'training' rivals that of the words 'must' and 'should' in the Guide; many times, they appear together, as in this phrase on page 17: "Training should be tailored to the particular needs of research groups." I envision several columns picking this fruit from the tree.

I would be remiss in not mentioning in this first column several organizations that are strong in training. For example, the American Society for Training and Development (ASTD; http://www.astd. org/) is well known among trainers for all disciplines, and we can glean examples and techniques from this group to apply to training of animal research personnel. Speaking of animal research training, the American Association for Laboratory Animal Science (AALAS; http://www.aalas.org/) has been premier in the development of training materials and technician certification, primarily in the US. But the concepts of training, and thereby the welfare of animals when used in research, extend to animal facilities around the world. The Laboratory Animal Welfare Training Exchange (LAWTE; http://www. lawte.org/) was started in 1994 (ref. 2) and has become the international training society devoted to laboratory animal technology. Future columns will focus on each of these institutional types of educational fruits.

Finally, it's worth noting that various groups look at the conduct, effectiveness and level of competency associated with training efforts. Years ago, the duty of training animal users was often added on to someone's job description-typically the manager'suntil the notion of institutional trainers became common ${ }^{3}$. Inspectors from the US Department of Agriculture, assurance staff from the Office of Laboratory Animal Welfare (US National Institutes of Health) and site visitors from the Association for the Assessment and Accreditation of Laboratory Animal Care (AAALAC) International, among others, are all reading protocols and other documents for descriptions of training and ability to carry out animal-related tasks. To wit, this topic (Training \& The Guide: Strategies for Success; sponsored by LAWTE) was discussed at the recent AALAS National Meeting in Minneapolis, MN.

Looking ahead to many topics relevant to training to write about, I hope that you'll 'bite the apple' and that it will be satisfying.

1. Institute for Laboratory Animal Research. Guide for the Care and Use of Laboratory Animals 8th edn. (National Academies Press, Washington, DC, 2011).

2. Pritt, S. \& Aranda, G. The history and future of the Laboratory Animal Welfare Training Exchange (LAWTE). ALN Magazine (March 2007).

3. Kennedy, B.W. Creating a training coordinator position. Lab Anim. (NY) 31, 34-38 (2002). 